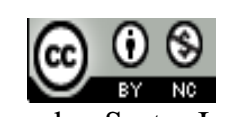

Jurnal Pendidikan Bahasa dan Sastra Indonesia is licensed under

A Creative Commons Attribution-Non Commercial 4.0 International License

\title{
Analisis Komponen Makna Verba "Menyakiti" dalam Bahasa Melayu Dialek Sambas (Kajian Semantik)
}

\author{
Zulfahita ${ }^{1)}$, Lili Yanti ${ }^{2)}$, Evi Purnamawati ${ }^{3)}$ \\ ${ }^{1)}$ Program Studi Pendidikan Bahasa dan Sastra Indonesia, STKIP Singkawang, \\ E-mail: zulfahita@yahoo.com \\ ${ }^{2)}$ Program Studi Pendidikan Bahasa dan Sastra Indonesia, STKIP Singkawang, \\ E-mail: lilivantiana18@gmail.com \\ ${ }^{3)}$ Program Studi Pendidikan Bahasa dan Sastra Indonesia, STKIP Singkawang, \\ E-mail: evipurnamawati321@gmail.com
}

\begin{abstract}
Abstrak. Masalah umum dalam penelitian ini adalah analisis komponen makna verba "menyakiti” dalam bahasa Melayu dialek Sambas. Penelitian ini bertujuan untuk mendeskripsikan klasifikasi komponen makna, makna leksikal, dan peran semantik yang dapat dilihat dengan menggunakan tangan, alat dan kaki. Kajian teori yang digunakan dalam penelitian ini ialah kajian semantik. Penelitian ini menggunakan metode deskriptif kualitatif. Sumber data penelitian ini yaitu masayarakat yang bertempat tinggal di Dusun Kokban Rt 012/Rw 006 Desa Bentunai Kecamatan Selakau Kabupaten Sambas. Data dalam penelitian ini adalah katakata yang mengandung verba "menyakiti" dalam bahasa Melayu dialek Sambas. Teknik pengumpulan data dalam penelitian ini adalah teknik cakap semuka, teknik rekaman dan teknik catat. Berdasarkan analisis data dan pembahasan dapat disimpulkan bahwa verba "menyakiti" dalam bahasa Melayu dialek Sambas terdapat 53 leksem yang berkenaan dengan verba "menyakiti" dalam bahasa Melayu dialek Sambas yang diklasifikasikan menjadi verba menyakiti menggunakan tangan 28 leksem, alat 18 leksem dan kaki 7 leksem. Verba "menyakiti" menggunakan tangan dikelompokkan menjadi lima diantaranya; menekan 9 leksem. menarik 3 leksem, memelintir 3 leksem, memukul 9 leksem, dan mendorong 3 leksem. Verba menyakiti menggunakan alat dikelompokkan menjadi tiga diantaranya; melempar 4 leksem, menusuk 3 leksem, dan memukul 11 leksem.
\end{abstract}

Kata Kunci : Melayu Sambas; Komponen Makna; Makna Leksikal; Peran Semantik

\section{PENDAHULUAN}

Bahasa merupakan alat komunikasi antara anggota masyarakat berupa simbol bunyi yang dihasilkan oleh alat ucap manusia, agar komunikasi yang dilakukan berjalan lancar dan baik. Penerima dan pengirim bahasa harus menguasai bahasanya. Nababah (dalam Aslinda \& Leni, 2014:11) menyatakan secara garis besar hakikat bahasa membicarakan sistem suatu unsur bahasa, sedangkan fungsi bahasa yang paling mendasar ialah untuk komunikasi. Komunikasi merupakan proses pernyataan perasaan seseorang kepada orang lain. Di dalam berkomunikasi dengan orang lain, tindak tutur merupakan produk dari suatu ujaran kalimat dalam kondisi tertentu dan merupakan kesatuan terkecil dari komunikasi bahasa yang menentukan makna kalimat (Safrihady \& Mardikantoro, 2017:60). Oleh karena itu, bahasa daerah perlu mendapat perhatian khusus, karena pada zaman sekarang begitu banyak hal yang dapat mempengaruhi perkembangan bahasa daerah.
Bahasa daerah adalah penamaan bahasa yang digunakan oleh kelompok orang yang anggota-anggotanya secara relatif memperlihatkan frekuensi interaksi yang lebih tinggi di antara mereka dibandingkan dengan mereka yang tidak bertutur dalam bahasa daerah tersebut (Masinambow \& Paul, 2002:52). Bahasa daerah memiliki peran dan pengaruh bagi kelangsungan bahasa Indonesia. Mengingat pentingnya fungsi bahasa bagi perkembangan bahasa Indonesia maka keberadaan bahasa daerah harus selalu di lestarikan agar bahasa daerah tetap terjaga keasliannya. Melayu dialek Sambas merupakan sub-etnis Melayu yang memiliki kekhasan dari segi bahasa, adat-istiadat, seni dan lain sebagainya (Mustansyir, 2015:8). Bahasa ini tumbuh dan berkembang di Kabupaten Sambas dan sampai saat ini masih terus dipelihara serta digunakan sebagai bahasa daerah oleh masyarakat Melayu dialek Sambas.

Pemilihan komponen makna verba "menyakiti" sebagai objek penelitian didasarkan atas beberapa pertimbangan antara lain: (1) Peneliti mengamati masyarakat di sana lebih 
menekankan kepada perbuatan atau tingkah laku yang terjadi dalam masyarakat penutur dalam berbahasa. (2) Verba "menyakiti" memiliki banyak kata yang dapat dimasukan ke dalam jangkauan makna atau komponen makna. (3) Peneliti mengetahui secara langsung klasifikasi kata verba "menyakiti" di dalam masyarakat Melayu dialek Sambas khususnya kata atau frasa yang hampir jarang digunakan oleh masyarakat Melayu dialek Sambas. (4) Peneliti ingin mendokumentasikan keaslian bahasa dan menggembangkan penggunaan bahasa Melayu dialek Sambas agar tetap berkembang dan dikenal oleh masyarakat luas dalam ilmu kebahasaan. (5) Bahasa Melayu dialek Sambas mempunyai keunikan dan kekhasan dari segi pengucapan dan penulisannya. Keunikan dan kekhasan itu tampak dalam verba "menyakiti" dalam bahasa Melayu dialek Sambas karena adanya perbedaan penggunaan lambang bunyi bahasa pada setiap kata yang dihasilkan. Alasan peneliti memilih memilih Desa Bentunai sebagai tempat penelitian karena masyarakat di Desa Bentunai mayoritas bersuku Melayu dan bahasa yang digunakan di desa tersebut bahasa Melayu dialek Sambas yang digunakan dalam kehidupan sehari-hari. Serta, penggunaan bahasa Melayu dialek Sambas masih sangat terjaga dialeknya bahkan masyarakat di sana tidak terpengaruh dengan penggunaan bahasa dari luar. Sehingga verba "menyakiti" dalam bahasa Melayu dialek Sambas menarik dan layak untuk dikaji oleh peneliti.

Penelitian ini bertujuan mengetahui klasifikasi komponen makna, makna leksikal dan peran semantik verba "menyakiti". Verba merupakan kelas kata terbuka. Kridalaksana (2008:254) menyatakan verba adalah kelas kata yang biasanya berfungsi sebagai predikat, dalam beberapa bahasa lain verba memiliki ciri morfologis seperti ciri kala, aspek, pesona, atau jumlah. Jadi verba merupakan kelas kata yang mewakili unsur semantik perbuatan, keadaan atau proses. Pendapat tersebut juga didukung oleh Mulyono (2013:19) menyatakan verba adalah semua kata yang menyatakan perbuatan atau tingkah laku.

Menurut Chaer (2013:114) menyatakan komponen makna atau komponen semantik mengajarkan bahwa setiap kata atau unsur leksikal terdiri dari satu atau beberapa unsur yang bersama-sama membentuk makna kata atau makna unsur leksikal. Komponen makna ini dapat dianalisis, dibutiri, atau disebutkan satu per satu, berdasarkan "pengertian-pengertian" yang dimilikinya, misalnya unsur (+insan) (+dewasa) (+jantan) (+kawin) dan sebagainya pada kata ayah dan ibu mengandung komponen makna: (+insan) (+dewasa) (-jantan) (+kawin).

Tabel 1 Komponen Makna "Menyakiti”

\begin{tabular}{lccc}
\hline Leksem & \multicolumn{3}{c}{ Komponen Makna } \\
Ciri Semantik & Tangan & Alat & Kaki \\
\hline 1. Pelaku & + & + & + \\
2. Sasaran & + & + & + \\
3. Posisi telapak tangan & + & + & - \\
4. Alat yang digunakan & + & + & - \\
5. Bagian kaki & - & - & + \\
\hline
\end{tabular}

Keterangan:

Tanda (+) memiliki komponen makan kata
Tanda (-) berarti tidak mempunyai komponen makna kata Makna leksikal adalah makna yang sesuai dengan referennya, makna yang sesuai dengan hasil observasi alat indera atau makna yang sungguh-sungguh nyata dalam kehidupan. Pateda (2010:119) menyatakan makna leksikal adalah makna kata ketika makna kata itu berdiri sendiri, baik dalam bentuk laksem atau bentuk berimbuhan yang maknanya kurang lebih tetap, seperti yang dapat dibaca di dalam kamus bahasa tertentu. Sejalan dengan pendapat yang telah dikemukakan oleh Pateda, Chaer (2013:60) menyatakan bahwa leksikal dapat diartikan sebagai makna yang bersifat leksikon, bersifat leksem, atau kata.

Peran semantik merupakan hubungan antara unsurunsur bahasa dilihat dari sudut pandang penyajiannya dalam ujaran. Kridalaksana (2008:187) menyatakan peran adalah hubungan antara predikator dengan sebuah nomina, sedangkan semantik adalah bagian struktur bahasa yang berhubungan dengan makna (Kridalaksana, 2008:216). Jadi peran semantik adalah hubungan antara predikat dengan nomina dalam membentuk makna. Peran semantik dibedakan menjadi enam yaitu, pelaku, sasaran, pengalaman, peruntung, atribut, dan peran semantik keterangan (Alwi, 2010:341-342).

a. Pelaku adalah peserta yang melakukan perbuatan yang dinyatakan oleh verba predikat.

b. Sasaran adalah peserta yang dikenal perbuatan yang dinyatakan oleh verba predikat.

c. Pengalaman adalah peserta yang mengalami keadaan atau peristiwa yang dinyatakan predikat. Peran pengalam merupakan peran unsur subjek yang predikatnya adjektiva atau verba taktransitif yang lebih menyatakan keadaan.

d. Peruntung adalah peserta yang beruntung dan memperoleh manfaat dari keadaan, peristiwa atau perbuatan yang dinyatakan oleh predikat.

e. Atribut adalah kalimat yang predikatnya nomina, predikat tersebut mempunyai peran semantik atribut.

f. Peran Semantik Keterangan adalah peran semantik yang terdapat pada fungsi keterangan, seperti keterangan waktu, keterangan tempat, keterangan alat, dan keterangan sumber.

\section{METODE}

Penelitian ini mengenai analisis komponen makna verba "menyakiti" di Desa Bentunai, Kecamatan Selakau, Kabupaten Sambas. Penelitian ini menggunakan metode penelitian deskriptif. Metode deskriptif adalah berupa katakata, gambar, dan bukan angka-angka (Moleong, 2017:11). Dengan demikian, laporan penelitian akan berisi kutipankutipan data untuk memberi gambaran penyajian laporan tersebut.

Bentuk penelitian yang digunakan dalam penelitian ini adalah bentuk penelitian kualitatif. Menurut Moleong (2017:6) menyatakan penelitian kualitatif adalah penelitian yang bermaksud untuk memahami fenomena tentang apa yang dialami oleh subjek penelitian misalnya perilaku, persepsi, motivasi, tindakan, dan lain-lain, secara holistik, dan dengan cara deskripsi dalam bentuk kata-kata dan bahasa, pada suatu konteks khusus yang alamiah dan dengan memanfaatkan berbagai metode alamiah. 
Sumber data dari penelitian ini adalah masyarakat yang berjumlah tiga orang sebagai informan dan mengetahui halhal yang berkaitan dengan verba "menyakiti" yang dilakukan oleh masyarakat Melayu Sambas yang bertempat tinggal di Dusun Kokban Rt 012/Rw 006 Desa Bentunai Kecamatan Selakau Kabupaten Sambas. Data dalam penelitian ini adalah kata atau frasa yang mengandung makna verba "menyakiti" pada bahasa Melayu dialek Sambas yang digunakan dalam tindakan dan komunikasi dalam kehidupan sehari-hari oleh masyarakat Melayu Sambas.

Teknik pengumpulan data yang digunakan peneliti dalam penelitian ini meliputi teknik cakap semuka, teknik rekam dan teknik catat. Alat pengumpul data yang sesuai digunakan dengan teknik pengumpulan data di atas adalah lembar pedoman wawancara, tape recorder atau alat perekam, dan kartu data.

Teknik analisis data yang digunakan dalam penelitian ini, memiliki tahapan, yaitu tahap persiapan data, tahap analisis data, dan tahap penyajian hasil analsis data. Sementara pengecekan keabsahan data yang digunakan dalam penelitian ini, yaitu triangulasi dan diskusi teman sejawat.

\section{HASIL DAN PEMBAHASAN}

HASIL

Pertama, data yang uraikan adalah data mengenai Klasifikasi komponen makna, makna leksikal dan peran semantik verba "menyakiti" dalam bahasa Melayu dialek Sambas Kajian Semantik.

\section{A. Klsifikasi Komponen Makna}

Komponen makna verba "menyakiti" diklasifikasikan menjadi tiga bagian yaitu menyakiti menggunakan tangan, alat, dan kaki. Klasifikasi tersebut akan dijabarkan berdasarkan dengan ciri-cirinya.

1. Komponen Makna Menyakiti Menggunakan Tangan

Klasifikasi "menyakiti" menggunakan tangan dalam bahasa Melayu dialek Sambas terdiri atas 28 leksem yang diklasifikasikan kembali menjadi 5 kelompok yaitu (a) menyakiti dengan cara menekan yaitu bakkok 'menekan', cakkal 'cekik',, cakkok 'cekik', gerammus 'cakar', kubik 'cubit', nyakar 'cakar', perakoh 'menekan', terakam 'cengkeram',dan tunjal 'menekan', b) menyakiti dengan cara menarik yaitu cabbau 'jambak', jujut 'jewer' dan sintak 'jambak', (c) menyakiti dengan cara memelintir yaitu pullas 'pelintir', purikkan 'pelintir', dan pulirkan 'pelintir', (d) menyakiti dengan cara memukul yaitu belampang 'tempeleng', jantek 'jentik', papah 'memepah', taggum 'memukul', tampar 'tampar', tappak 'menepuk', tappek 'memukul', tikkak 'jitak', tukok 'menokok', dan tumbok 'tinju' dan (e) menyakiti dengan cara mendorong yaitu nyigong 'sigung', tingkape 'mendorong' dan tulakkan 'mendorong'.

a. Menyakiti dengan Cara Menekan

1) Bakkok [bak:o?]

Verba bakok [bak:o?] memiliki komponen makna Sasaran; - kepala, + leher, - mulut, - badan, pipi, - tangan; Bagian tangan yang digunakan; + tangan, + ibu jari, + jari telunjuk, + kuku/ujung jari, + telapak; Telapak tangan; + melingkar di sasaran, - terbuka, - setengah melingkar di sasaran, + menutup di sasaran; + dengan tekanan kuat. Berdasarkan komponen makna di atas terdapat ciriciri sasaran bagian + leher, bagian tangan yang digunakan + tangan, + ibu jari, + jari telunjuk, + kuku/ujung jari, + telapak, posisi telapak tangan + melingkar di sasaran, + menutup di sasaran, + dengan tekanan kuat.

Berdasarkan komponen makna tersebut verba bakok [bak:o?] adalah perbuatan "menyakiti" menggunakan tangan dengan posisi telapak melingkar atau menutup pada leher dengan tekanan kuat.

b. Menyakiti dengan Cara Memukul

1) Tumbok [tumbo?]

Verba tumbok [tumbo?] memiliki komponen makna sasaran; + kepala, - pipi, - mulut, + bahu, + badan, - telinga, - pantat; bagian yang digunakan + jari, - telapak tangan, + buku tangan; posisi tangan + menggepal, - terbuka, + ujung jari menempel pada ujung telapak. Berdasarkan komponen makna di atas terdapat ciri-ciri sasaran bagian + kepala, + bahu, + badan, bagian yang digunakan + jari, + buku tangan, posisi tangan + menggepal, + ujung jari menempel pada ujung telapak.

Berdasarkan komponen makna tersebut verba tumbok [tumbo?] adalah perbuatan "menyakiti" menggunakan tangan dengan memukul bagian kepala menggunakan buku tangan dengan posisi tangan mengepal.

c. Menyakiti dengan Cara Mendorong

1) Nyigong [nigon]

Verba nyigong [nigon] memiliki komponen makna sasaran; - kepala/dahi, + badan, + tangan; bagian yang digunakan; - ujung jari, - telapak tangan, + siku, - badan; + dengan cara didorong kuat. Berdasarkan komponen makna di atas terdapat ciri-ciri sasaran bagian + badan, + tangan, bagian yang digunakan + siku, + dengan cara didorong kuat.

Berdasarkan komponen makna tersebut verba nyigong [nigon] adalah perbuatan "menyakiti" menggunakan tangan dengan cara mendorong bagian badan atau tangan yang menjadi sasaran mengguakan siku mendorong dari samping dengan tekanan yang kuat.

2. Komponen Makna Menyakiti Menggunakan Alat

Klasifikasi "menyakiti" menggunakan alat dalam bahasa Melayu dialek Sambas terdiri atas 18 leksem yaitu diklasifikasikan kembali menjadi 3 kelompok yaitu (a) menyakiti dengan cara melempar yaitu badab 'melempar', lontarkan 'lempar', pantinge 'melempar', dan patek 'memukul', (b) menyakiti dengan cara menusuk yaitu tikam 'menusuk', tonyoh 'menusuk', dan tutjah 'menusuk', dan (c) menyakiti dengan cara memukul yaitu ambat 'cambuk', bantai 'memukul', basut 'memukul', cabik 'menggait', catok 'memukul', kabbas 'memukul', 
kibbau 'memukul', ngampok 'memukul', nukkok 'menokok', pangkong 'pangkung', dan rimpat 'sebat'.

a. Menyakiti Menggunakan Alat dengan Melempar

1) Badab [badab]

Verba badab [badab] memiliki komponen makna + sasaran tak tentu; arah gerakan - samping, + datar, - bawah, - atas; alat yang digunakan - kayu, - batu, - karet, + bola. Berdasarkan komponen makna di atas terdapat ciri-ciri + sasaran tak tentu; arah gerakan + datar, alat yang digunakan + bola.

Berdasarkan komponen makna tersebut verba badab [badab] adalah perbuatan "menyakiti" menggunakan alat dengan cara melempar dengan sasaran tak tentu menggunakan gerakan yang datar alatnya seperti bola.

b. Menyakiti Menggunakan Alat dengan Menusuk

1) Tutjah [tot $\left.t^{j}\right]$

Verba tutjah [totjah] memiliki komponen makna sasaran; + badan, - mata, arah gerakan; datar, + bawah, - samping, genggaman tangan; + erat, - longgar; alat + tajam, + runcing. Berdasarkan komponen makna di atas terdapat ciri-ciri sasaran + badan, arah gerakan + bawah, genggaman tangan + erat, alat + tajam, + runcing.

Berdasarkan komponen makna tersebut verba tutjah [totjah] adalah perbuatan "menyakiti" menggunakan alat dengan cara menusuk bagian badan menggunakan arak gerakan bagian bawah dengan genggaman tangan erat menggunakan alat tajam dan runcing.

c. Menyakiti Menggunakan Alat dengan Memukul

1) Rimpat [rimpat]

Verba rimpat [rimpat] memiliki komponen makna sasaran; + badan, + kaki, - kepala, - tangan; arah + atas ke bawah, + samping/datar, alat; - benda tajam, + benda tumpul, + benda kecil; + dipukulkan dengan kuat. Berdasarkan komponen makna di atas terdapat ciri-ciri sasaran + badan, + kaki, arah + atas ke bawah, + samping/datar, alat + benda tumpul, + benda kecil + dipukulkan dengan kuat.

Berdasarkan komponen makna tersebut verba rimpat [rimpat] adalah perbuatan "menyakiti" menggunakan alat dengan cara memukul pada sasaran badan dan kaki menggunakan gerakan yang bebas dengan alat yaitu benda tumpul dengan ukuran yang kecil dengan sangat kuat.

3. Komponen Makna Menyakiti Menggunakan Kaki

Klasifikasi "menyakiti" menggunakan kaki dalam bahasa Melayu dialek Sambas terdiri atas 7 leksem. Adapun data dari verba "menyakiti" menggunakan kaki adalah kacak 'injak', kapik 'menekan', kaiskan 'mendorong', kating 'mendorong', pantong 'mendorong', sepak 'menyepak', dan teratjang 'terjang'.

1) Pantong [panton]

Verba pantong [panton] memiliki komponen makna sasaran; - bagian atas tubuh, + bagian bawah tubuh; bagian kaki yang digunakan + telapak, + ujung jari kaki, - pinggiran telapak, - tumbit; bagian telapak; + terbuka ke arah sasaran, - menekan ke bawah, + ke arah samping. Berdasarkan komponen makna di atas terdapat ciri-ciri sasaran + bagian bawah tubuh, bagian kaki yang digunakan + telapak, + ujung jari kaki, bagian telapak; + terbuka ke arah sasaran, + ke arah samping.

Berdasarkan komponen makna tersebut verba pantong [panton] adalah perbuatan "menyakiti" menggunakan kaki dengan sasaran bagian bawah tubuh menggunakan telapak, dan ujung jari kaki, dengan terbuka ke arah sasaran.

\section{B. Makna Leksikal}

1. Menyakiti Menggunakan Tangan

a. Bakkok [bak:o?] menekan (v) kata tersebut bermakna "menyakiti" dengan cara menekan bagian leher menggunakan dua belah tangan dengan posisi bagian tangan menutupi daerah sasaran.

b. Cabbau [cab:av] jambak (v) kata tersebut bermakna "menyakiti" dengan cara menarik menggunakan jari dan telapak tangan dengan tekanan yang kuat dan erat sehingga yang menjadi sasaran yaitu rambut.

c. Kubik [kobi?] cubit (v) kata tersebut bermakna "menyakiti" dengan cara menekan dan menjepit di antara dua jari telunjuk dan jari lain dengan sasaran bagian pipi, badan, dan tangan.

d. Nyigong [nigon] sigung (v) kata tersebut bermakna "menyakiti" dengan menyentuh (menumbuk, mendorong, dsb) dengan siku; menyiku; menyinggung, sasaran tangan dan badan.

e. Terakam [tcrakam] mencengkam (v) kata tersebut bermakna "menyakiti" dengan cara menekan 1 . memegang erat-erat dengan cakar (kuku); 2 menjepit (mengapit); sasaran muka.

2. Menyakiti Menggunakan Alat

a. Badab [badab] memukul (v) kata tersebut bermakna "menyakiti" dengan cara melempar bola ke semua sasaran (bebas sasaran) di bagian badan dengan menggunakan bola ke arah datar.

b. Kabbas [kab:as] memukul (v) kata tersebut bermakna "menyakiti" dengan cara memukul dengan menggunakan kain atau baju ke arah atas ke bawah dan samping atau datar dengan sasaran bagian kepala dan badan.

c. Pantinge [pantine] melempar (v) kata tersebut bermakna "menyakiti" dengan cara melempar atau mengayunkan benda ke arah yang bebas seperti kayu dan batu dengan sasaran bagian tubuh.

d. Rimpat [rimpat] sebat (v) menyakiti dengan memukul menggunakan benda tumpul dan kecil seperti rotan, dengan sasaran pantat, badan, dan kaki. Rimpat biasanya digunakan untuk memarahi anak yang nakal.

e. Tutjah [tu $\mathrm{t}^{\mathrm{j}}$ ] menusuk (v) menyakiti dengan cara menusuk dengan benda tumpul seperti rotan, galah, atau tongkat ke arah bawah dengan sasaran bagian badan dengan tekanan yang erat. 
3. Menyakiti Menggunakan Kaki

a. Kacak [kaca?] meninjak (v) menyakiti dengan cara meninjak bagian badan dengan langkah yang keras menggunakan telapak kaki.

b. Katting [kat:in] mendorong (v) kata tersebut bermakna "menyakiti" dengan cara mendorong bagian ujung jari dan telapak kaki ke arah belakang menggenai kaki dengan tekanan kuat.

c. Pantong [panton] mendorong (v) kata tersebut bermakna menyakiti mendorong di bagian telapak kaki dan ujung kaki ke arah samping dengan posisi terbuka ke arah sasaran dan mengenai kaki.

d. Sepak [sepak] menyepak (v) menyakiti dengan memukul sesuatu dengan menggunakan kaki; menendang dengan cara mengayunkan kaki dengan gerakan ke atas maupun ke bawah.

e. Teratjang [tcratjay] menerjang (v) menyakiti dengan menendang (terutama ke bawah atau ke depan) dengan telapak kaki. Dia hampir pencuri itu.

\section{Peran Semantik}

1. Menyakiti Menggunakan Tangan

a. Leksem kubik mempunyai peran semantik untuk menyakiti, memarahi seseorang agar tidak nakal. Contoh peran semantik sebagai berikut.

1. Peran Semantik Pelaku

Nenek ngubik tangan Linda barang jak soso.

"Nenek mencubit tangan Linda karena nakal."

Contoh kalimat di atas memiliki peran semantik di mana Nenek sebagai pelaku, karena melakukan perbuatan cubit.

2. Peran Semantik Sasaran

Rahman kannak kubik badannye gare-gare bolos sekolah.

"Rahman di cubit badannya karena bolos sekolah."

Contoh kalimat di atas memiliki peran semantik di mana badan sebagai sasaran, karena yang terkena oleh perbuatan dari pelaku.

3. Peran Semantik Pengalaman

Tangan Vara sampai merah kannak kubik

"Tangan Vara memerah karena di cubit."

Contoh kalimat di atas memiliki peran semantik di mana Vara sebagai pengalaman karena yang mengalami keadaan atau peristiwa.

4. Peran Semantik Keterangan

Umak ngubik tangan Iing semari.

"Ibu mencubit tangan Iing kemarin."

Contoh kalimat di atas memiliki peran semantik di mana di kemarin sebagai peran semantik keterangan karena menyatakan keterangan waktu.

2. Menyakiti Menggunakan Alat

a. Leksem rimpat mempunyai peran semantik untuk menyakiti supaya anak tidak melakukan kesalahan yang sama lagi. Contoh peran semantik sebagai berikut.

1. Peran Semantik Pelaku

Danu kannak rimpat lah Umaknye barang jak minum arak.
"Danu di sebat oleh Ibunya karena minum alkohol."

Contoh kalimat di atas memiliki peran semantik di mana Ibu sebagai pelaku, karena melakukan perbuatan sebat.

2. Peran Semantik Sasaran

Kurnia kannak rimpat badanye bebakas.

"Kurnia di sebat badannya sampai berbekas."

Contoh kalimat di atas memiliki peran semantik di mana badan sebagai sasaran, karena yang terkena oleh perbuatan dari pelaku.

3. Peran Semantik Pengalaman

Badan Yanto matu darah barang kannak rimpat.

"Badan Yanto memar karena di sebat."

Contoh kalimat di atas memiliki peran semantik di mana Yanto sebagai pengalaman karena yang mengalami keadaan atau peristiwa.

\section{Peran Semantik Keterangan}

Badan Rino di rimpat Bapaknye semalam pakai rotan sampai mattu darah barang jak soso.

"Badan Rino di sebat Bapaknya kemarin menggunakan rotan sampai memar karena nakal."

Contoh kalimat di atas memiliki peran semantik di mana kemarin adalah peran semantik keterangan untuk menunjukkan keterangan waktu. Sedangkan rotan adalah peran semantik keterangan untuk menunjukan keterangan sumber yaitu alat yang digunakan.

3. Menyakiti Menggunakan Kaki

a. Leksem teratjang mempunyai peran semantik untuk menyakiti supaya terlempar. Contoh peran semantik sebagai berikut.

1. Peran Semantik Pelaku

Angga teratjang batis Hendi barang jak kelaikan maingan.

"Angga menerjang betis Hendi karena mengkelahikan mainan."

Contoh kalimat di atas memiliki peran semantik di mana Angga sebagai pelaku, karena melakukan perbuatan menerjang.

2. Peran Semantik Sasaran

Tukang parkir kannak teratjangkan kakinye sampai patah.

"Tukang parkir di terjang kakinya sampai patah." Contoh kalimat di atas memiliki peran semantik di mana kaki sebagai sasaran, karena yang terkena oleh perbuatan dari pelaku.

3. Peran Semantik Pengalaman

Rusman teratjang batis Kiki sampai kambang.

"Rusman menerjang betis Kiki sampai kembang."

Contoh kalimat di atas memiliki peran semantik di mana Pencuri sebagai pengalaman karena yang mengalami keadaan atau peristiwa.

4. Peran Semantik Keterangan 
Fitria terjang kaki Uni semari di sekolah barang jak kelai.

"Fitria menerjang kaki Uni kemarin di sekolah karena kelahi."

Contoh kalimat di atas memiliki peran semantik di mana kemarin adalah semantik keterangan menyatakan keterangan waktu. Sedangkan di sekolah adalah semantik keterangan menyatakan keterangan tempat.

\section{SIMPULAN DAN SARAN}

\section{SIMPULAN}

Berdasarkan hasil penelitian analisis komponen makna verba "menyakiti" dalam bahasa Melayu dialek Sambas Kajian Semantik, maka dapat simpulan sebagai berikut.

1. Komponen makna terdapat 53 leksem yang berkaitan dengan verba "menyakiti" yang diklasifikasi menjadi 3 bagian, (1) menyakiti menggunakan tangan 28 leksem di bagi menjadi 5 kelompok yaitu (a) menekan 9 leksem, (b) Menarik 3 leksem, (c) memelintir 3 leksem, (d) memukul 9 leksem, (e) mendorong 3 leksem. (2) menyakiti menggunakan alat 18 leksem di bagi menjadi 3 kelompok yaitu (a) melempar 4 leksem, (b) menusuk 3 leksem, (c) memukul 11 leksem, (3) menyakiti menggunakan kaki 7 leksem.

2. Makna leksikal mempunyai 53 makna diantaranya; verba "menyakiti" menggunakan tangan yaitu, belampang, bakkok, cabbau, cakkal, cakkok, gerammus, jujut, jantek, kubik, nyakar, nyigong, papah, perakoh, pullas, purikkan, pulirkan, sintak, taggum, tampar, tappak, tappek, terakam, tikkak, tingkape, tukok, tulakkan, tumbok, tunjal. Verba "menyakiti" menggunakan alat yaitu ambat, badab, bantai, basut, cabik, catok, kabbas, kibbau, lontarkan, ngampok, nukkok, pangkong, pantinge, patek, rimpat, tikam, tonyoh, tutjah. Sedangkan verba "menyakiti" menggunakan kaki yaitu kacak, kapik, kaiskan, katting, pantong, sepak 'menyepak', teratjang.

3. Peran Semantik mempunyai peran peran semantik berjumlah 53 leksem yang terbagi menjadi empat yaitu, pelaku, sasaran, pengalaman, dan peran semantik keterangan.

\section{SARAN}

Adapun saran yang dapat direkomendasikan adalah sebagai berikut.

1. Dengan adanya penelitian ini dapat menambah wawasan pembaca mengenai verba "menyakiti" dalam bahasa Melayu dialek Sambas.

2. Penelitian yang dilakukan dapat dijadikan dokumentasi pelestarian bahasa daerah bagi masyarakat Melayu Sambas.

\section{DAFTAR PUSTAKA}

Alwi, H. (2010). Tata Bahasa Baku Bahasa Indonesia. Jakarta: Balai Pustaka.
Arsyad, A. (2013). Media Pembelajaran. Jakarta: PT Raja Grafindo Persada.

Aslinda \& Leni. S. (2014). Pengantar Sosiolinguistik. Bandung: PT Refika Aditama.

Chaer, A. (2013). Pengantar Semantik Bahasa Indonesia. Jakarta: Rineka Cipta.

Kridalaksana, H. (2008). Kamus Linguistik Edisi Keempat. Jakarta: Gramedia Pustaka Utama.

Mahsun. (2013). Metode Penelitian Bahasa: Tahapan Strategi, Metode, dan Tekniknya. Jakarta: Rajawali Pers.

Masinambow \& Paul. H. (2002). Bahasa Indonesia dan Bahasa Daerah. Jakarta: Yayasan Obor Indonesia.

Moleong, L. J. (2017). Metodologi Penelitian Kualitatif. Bandung: PT Remaja Rosdakarya.

Mustansyir, R. (2015). Kearifan Lokal Masyarakat Melayu Sambas Dalam Tinjauan Filosofis.

Parera, J.D. (2004). Teori Semantik Edisi Kedua. Jakarta: Erlangga.

Pateda, M. (2010). Semantik Leksikal. Jakarta: Rineka Cipta.

Safrihady, S., \& Mardikantoro, H. B. (2017). Jenis dan Fungsi Pragmatis Tindak Tutur Masyarakat Melayu Dialek Sambas di Kota Singkawang. Seloka: Jurnal Pendidikan Bahasa Dan Sastra Indonesia, 6(1), 59-67.

Sudaryanto. (2015). Metode dan Aneka Teknik Analisis Bahasa. Yogyakarta: Sanata Dharma University. 